\title{
Optimization of the indirect fluorimetric detection for the simultaneous analysis of inorganic anions and polycharged organic anions by capillary electrophoresis
}

\author{
P.L. Desbène*, C. Morin and A. Desbène \\ Laboratoire d'Analyse des Systèmes Organiques Complexes, I.R.C.O.F. et I.F.R. $n^{\circ} 23$, Université de Rouen, \\ 43 rue Saint-Germain, 27000 Evreux, France
}

\begin{abstract}
Until now, fluorescein sodium salt has been used to generate the background signal for indirect fluorimetric detection of inorganic cations or mono-charged organic anions separated by Capillary Zone Electrophoresis (CZE). In this paper, we extend the use of fluorescein sodium salt to the simultaneous $\mathrm{CZE}$ analysis of inorganic anions $\left(\mathrm{Cl}^{-}, \mathrm{NO}_{2}^{-}, \mathrm{NO}_{3}^{-}, \mathrm{SO}_{4}^{2-}, \mathrm{F}^{-}\right)$and polycharged organic anions (oxalate and citrate). The electroosmotic flow was reversed by using tetradecyltrimethylammonium bromide (TTAB) or hexadimethrine. The specific problems linked to the simultaneous utilization of fluorescein sodium salt and a positively charged capillary were studied and resolved by reducing the fluorescein/TTAB interactions and by optimizing the fluorophore concentration in the electrolyte. The study of reproducibility and the quantitative approach led to very good results. In such conditions the quantification of $\mathrm{Cl}^{-}, \mathrm{NO}_{3}^{-}$and $\mathrm{SO}_{4}^{2-}$, in different mineral and spring waters, has been successfully realized. In addition, the detection thresholds reached the range of one hundred to a few hundred ppb.
\end{abstract}

Key words. Capillary zone electrophoresis - indirect fluorimetric detection - fluorescein sodium salt - inorganic anions polycharged organic anions.

\section{Introduction}

Liquid Phase Chromatography is still considered today as a predilection technique for the inorganic anions analysis in several domains such as: environment, clinical diagnosis or food industry. Ions exchangers columns are used for the separation of these species, the detection being performed essentially by conductometry [1] and sometimes by indirect photometric detection [2]. However these techniques, although being still commonly used, compete more and more with High Performance Capillary Electrophoresis (HPCE), a relatively recent analytical technique that matches up a small cost of utilization, a certain facility of implementation and very high performances.

In the case of bare fused silica capillary, the electrophoretic mobility of inorganic anions is diametrically opposed to the electroosmotic flow. As a result, if a complex mixture containing inorganic anions with a wide range of electrophoretic mobilities is analyzed, some of these anions will never reach the detection window whatever the injection (anodic or cathodic). To prevent this analytical problem three strategies can be envisaged. The first one is based upon the use of a strong electroosmotic flow [3,4] in order to obtain a satisfactory separation rate. This strategy shows however some limitations, anions presenting a very high electrophoretic mobility not being able to be analyzed. The second one consists in the reduction or the suppression of the electroosmotic flow [5-15], detection and injection being respectively performed near the anode and at the cathode. Nevertheless for the inorganic anions and polycharged organic anions analysis, a third strategy is currently the most frequently used, the use of cationic surfactants:
- either to coat positively the capillary walls and so to reverse the electroosmotic flow allowing the visualization of all anions, whatever be their electrophoretic mobility [16-38],

- or to constitute micelles and so to analyze these inorganic ions by Micellar ElectroKinetic Chromatography [39].

Many cationic surfactants, generally quaternary ammonium surfactants, can be used as an electroosmotic flow reverser. For instance OFM Anion - BT [16-18,32,35], cetyltrimethylammonium (CTAB) [21-25,36,37], hexamethonium $[20,27,28,34]$ or trimethyltetradecylammonium (TTAB) [27, 29-31,33,36-38] can be noted.

Concerning the detection of inorganic anions separated by HPCE, we can observe, according to literature data, almost no loss of sensitivity as compared to Liquid Phase Chromatography. Several detection methods have been used, including amperometric detection in non aqueous media [14] or suppressed conductivity detection [4]. Nevertheless the direct or indirect photometric detection methods are mainly employed. The direct UV detection applies unfortunately only to a few number of inorganic anions such as $\mathrm{Br}^{-}, \mathrm{I}^{-}$, $\mathrm{NO}_{2}^{-} \mathrm{NO}_{3}^{-}$and $\mathrm{SCN}^{-}[19,24,25,33,36,39-44]$. On the other hand, the indirect UV detection appears more attractive due to its universality. The chromophore commonly introduced into the electrolyte to generate the background signal is the chromate [12,16-18,21,27,29,31,37]. However the utilization of dichromate [11,30,34], phtalate [7,14,20], pyromellitic acid [20,26,27] or polysulfonated naphtalenes [8] can be also noted. The introduction of these chromophores into the electrolyte often being matched by the addition of a quaternary ammonium surfactant, used as electroosmotic flow reverser, it is important to insure that incompatibility does 
not exist between these two components of the electrophoretic system, as is the case for the vanadium salts, that precipitate in front of some quaternary ammonium salts [16]. Otherwise the indirect fluorimetric detection, although less used, offers interesting potentialities concerning the sensitivity, for example in the case of the analyses of eleven priority phenols [45], of isopropenylpyrophosphates [46], of explosives [47] or of triorganotin compounds [48]. It has already been used for the analysis of inorganic anions, without reversion of the electroosmotic flow, by using detectors specially conceived for these applications $[3,6,9]$.

The aim of this study is to evaluate the potentialities of the first commercially available fluorimetric detector for the analysis of inorganic and polycharged organic anions, without any modification of the equipment. These analyses have been carried out with an eletroosmotic flow modifier (TTAB or hexadimethrine), the fluorescein sodium salt being used as fluorophore generating the background signal, as we have previously proposed for the analysis of inorganic cations [49] and for the analysis of monocharged organic anions [50]. In this original approach, the detection sensitivity was studied and the technique was applied to the quantification of anions $\left(\mathrm{Cl}^{-}, \mathrm{NO}_{2}^{-}\right.$and $\left.\mathrm{SO}_{4}^{2-}\right)$ in different mineral and spring waters.

\section{Experimental part}

\section{Reagents}

All solutions were prepared by using $18 \mathrm{M} \Omega$ water produced by an Alpha Q purification system (Millipore, Bedford, MA, USA). Trimethyltetradecylammonium bromide (TTAB) and 1,5-dimethyl-1,5-diaza undecamethyl polymethobromide (hexadimethrine), used as electroosmotic flow reverser, were purchased from Janssen Chimica (Janssen Chimica, Noisy le Grand, France). On the other hand, all reagents, used for the preparation of buffer solutions and for the preparation of inorganic and organic anions standard solutions presented analytical purity and were provided by Aldrich (Aldrich France, La Verpillière, France). All these reagents were used without purification.

\section{Apparatus}

All analyses were carried out by using a P/ACE 2100 system (Beckman, Fullerton, CA, USA) fitted with a fluorimetric detector using an Argon laser (excitation wavelength $=$ $488 \mathrm{~nm}$, emission wavelength $=520 \mathrm{~nm}$ ). The acquisition and the processing of data were performed with a PS/2 computer (IBM, Greenwock, UK) and of a P/ACE or GOLD 7.11 software (Beckman). Samples were injected in hydrodynamic mode (injection pressure: 0.5 psi, i.e. $3447 \mathrm{~Pa}$ ). A fused silica capillary ( $50 \mu \mathrm{m}$ i.d., $57 \mathrm{~cm}$ total length, $50 \mathrm{~cm}$ effective length) was used. Injections were operated at the cathodic end of this capillary whose temperature was fixed at $25{ }^{\circ} \mathrm{C}$. The $\mathrm{pH}$ of the separational buffers was systematically controlled before use, at the operating temperature, by means of a $\phi$ model pHmeter (Beckman). The study of the evolution of the fluorescence intensity as a function of the TTAB concentration was performed out line by using a LS-5 spectrofluorimeter (Perkin-Elmer Ltd, Beaconsfield, UK).

\section{Results and discussion}

The first studies mentioned in this paper were carried out by introducing into the buffer solutions the fluorophore (i.e. the fluorescein sodium salt) at $10^{-5} \mathrm{M}$. Indeed this concentration appeared to be during our previous works, performed without any electroosmotic flow modifier [49,50], the optimal concentration in regard of the concentration limit of detection (LOD). Similarly, the $\mathrm{pH}$ of the running buffer was fixed to 8.5 during these first approaches since this $\mathrm{pH}$ is perfectly suited to the utilization range of the fluorophore [49].

\section{Capillary coating}

The electroosmotic flow reversion for the analysis of polycharged inorganic anions is commonly carried out [16-38] to solve problems linked to their electrophoretic mobilities which are in opposite direction in regard of the electroosmotic flow, when a bare fused silica capillary is used.

At first, the electroosmotic flow reversion was intended by means of a quaternary ammonium salt, i.e. trimethyltetradecylammonium bromide (TTAB). When such an electroosmotic flow modifier is used, it is generally added into the running electrolyte at the same concentration as that used to coat the capillary walls so as to insure the maximal stability of this coating. Such conditions are unsuitable for the use of fluorescein as the component providing the fluorescence background signal. Indeed, in regard of the fluorescence, the TTAB/fluorescein interaction is similar to that of the acidic media impact, i.e. a loss of the detection sensitivity due to the neutralization of the negative charge of fluoresceinate anion [49]. This hypothesis has been verified by comparing the fluorescence intensity generated by the fluorescein with and without TTAB into the running buffer. So to prevent problems due to the surfactant desorption from the walls, caused by a too weak TTAB concentration into the carrier electrolyte, the coating time had to be optimized in order to perform several consecutive and reproducible analyses.

The coating time optimization was carried out by the following procedure:

i) First of all, the capillary was flushed by sodium hydroxyde $0.1 \mathrm{M}$ during 20 minutes, followed by a rinsing with water for 10 minutes.

ii) The fused silica capillary activation step being completed, the second step of the capillary coating was based on the equilibration of the silica surface with the running electrolyte, i.e. $\mathrm{H}_{3} \mathrm{BO}_{3} 10^{-1} \mathrm{M} / \mathrm{Na}_{2} \mathrm{~B}_{4} \mathrm{O}_{7} 2 \times 10^{-2} \mathrm{M} \mathrm{pH}=8.5$, by rinsing the capillary with this buffer for 20 minutes.

iii) Finally the effective coating was obtained by a flushing, whose duration remains to be optimized, with the running electrolyte supplemented with trimethyltetradecylammonium bromide $\left(5 \times 10^{-4} \mathrm{M}\right)$ and fluorescein sodium salt $\left(10^{-5} \mathrm{M}\right)$. The effective reversion of the electroosmotic flow was controlled by injection of water. Such a behaviour totally agreed with previously data of the literature [36,51].

Results obtained using a test mixture, containing 5 inorganic anions $\left(\mathrm{F}^{-}, \mathrm{Cl}^{-}, \mathrm{NO}_{2}^{-}, \mathrm{NO}_{3}^{-}\right.$and $\left.\mathrm{SO}_{4}^{2-}\right)$ and 2 polycharged organic anions (citrate and oxalate), are reported in figure 1. In fact, citrate and oxalate anions can raise 
$\mathbf{A}_{1}$

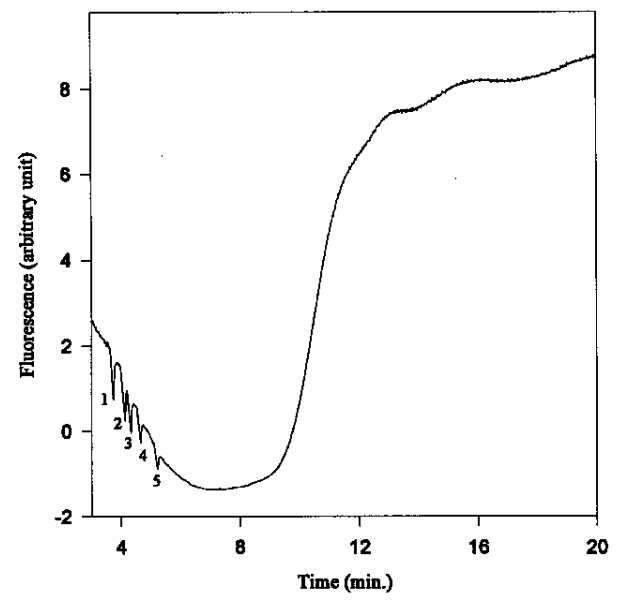

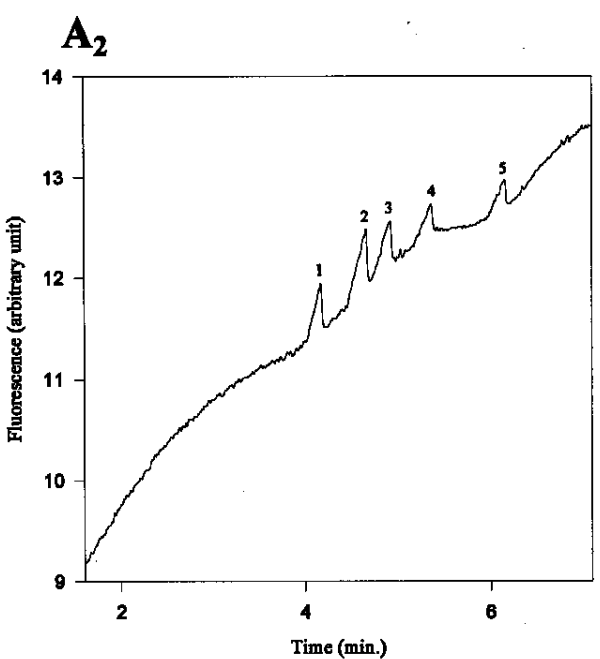

B

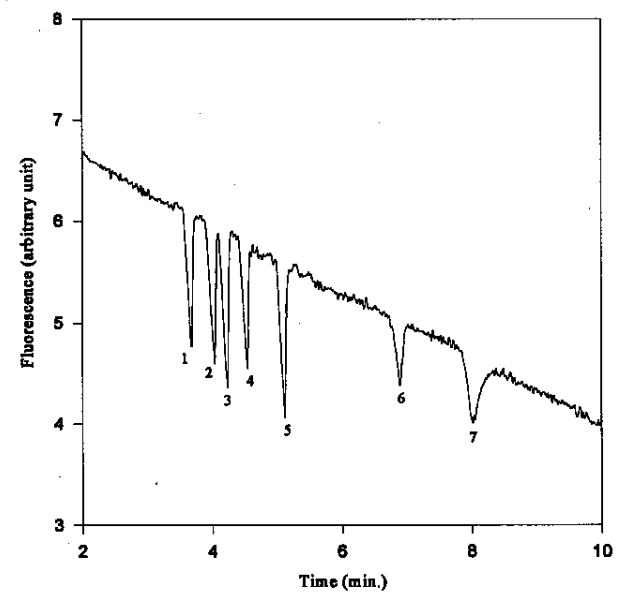

Fig. 1. Evolution of the detection of a test mixture containing inorganic anions and polycharged organic anions separated by $\mathrm{CZE}$ as a function of the capillary coating time. Operating conditions: Fused silica capillary $\left(50 \mu \mathrm{m} \mathrm{i.d.} \times 57 \mathrm{~cm}\right.$ length); temperature $25{ }^{\circ} \mathrm{C}$; applied voltage $20 \mathrm{kV}$; coating electrolyte: $\mathrm{H}_{3} \mathrm{BO}_{3} \times 10^{-1} \mathrm{M} / \mathrm{Na}_{2} \mathrm{~B}_{4} \mathrm{O}_{7} 2 \times 10^{-2} \mathrm{M}(\mathrm{pH}=8.5)$, [TTAB] $=5 \times 10^{-4} \mathrm{M}$ and [Fluorescein] $=10^{-5} \mathrm{M}$; running electrolyte: $\mathrm{H}_{3} \mathrm{BO}_{3} 10^{-1} \mathrm{M} / \mathrm{Na}_{2} \mathrm{~B}_{4} \mathrm{O}_{7} 2 \times 10^{-2} \mathrm{M}(\mathrm{pH}=8.5)$, [TTAB] $=10^{-5} \mathrm{M}$, [Fluorescein] = 10 $0^{-5} \mathrm{M}$. Hydrodynamic injection: $4 \mathrm{~s}$; Test mixture: (1) $\left[\mathrm{Cl}^{-}\right]=1.8 \mathrm{mM},(2)\left[\mathrm{NO}_{2}^{-}\right]=2.9 \mathrm{mM},(3)\left[\mathrm{NO}_{3}^{-}\right]=1.8 \mathrm{mM}$, (4) $\left[\mathrm{SO}_{4}^{2-}\right]=0.9 \mathrm{mM}$, (5) $[\mathrm{oxalate}]=0.9 \mathrm{mM}$, (6) $\left[\mathrm{F}^{-}\right]=1.2 \mathrm{mM}$ and (7) [citrate] $=0.6 \mathrm{mM}$. A) Coating time: 50 minutes. a. Rinsing with the carrier electrolyte: 10 minutes, b. First analysis of the test mixture (Electropherogram $\mathrm{A}_{1}$ ). c. Rinsing with the running electrolyte: 10 minutes, d. Second analysis of the test mixture (Electropherogram $\mathrm{A}_{2}$ ). B) Coating time: 2 hours. a) Rinsing with the running electrolyte: 10 minutes, b. Analysis of the test mixture (Electropherogram B).

analytical difficulties similar to that mentioned in the case of inorganic anions since their electrophoretic mobilities are equally high.

It appears on the electropherogram in figure $1 \mathrm{~A}_{1}$ that, when the coating time reaches 50 minutes, analyzed anions are visualized as negative peaks, in agreement with the theoretical development previously reported [49,50]. Moreover, a negative drift of the baseline is observed for analysis times inferior to 8 minutes. This drift results from the fluorescein adsorption on the capillary walls, that are now positively charged due to the TTAB hemimicelles. After 8 minutes of analysis, the baseline drift becomes positive and tends to stabilize. Such a behavior may be attributed to the partial shielding of positively charged walls by fluorescein. However this adsorption of fluorescein had only a little impact on the amplitude of the electroosmotic flow which is difficult to estimate because of the very low concentration of fluorescein as compared to that of TTAB.

Then, a second analysis of this test mixture was carried out, without the coating step. The obtained electropherogram is reported in figure $1 \mathrm{~A}_{2}$. First we can note simultaneously a positive drift of the baseline and the visualization of the analyzed solutes as positive peaks. Such a behavior may be ascribed to fluorescein desorption from the capillary surface. Indeed the return of the fluorescein within the running buffer, as TTAB/fluorescein ion pair, easily explains the positive drift of the baseline. Secondly, as a result of the presence of these TTAB/fluorescein ions pairs in solution, a 
competitive ion exchange between analyzed anions and fluoresceinate anions can take place. These ions exchanges are probably favored by the negative charge, more localized in the case of the studied anions than with fluoresceinate ions, which were released into the solution in large amount in the migration zone of the solutes. As previously shown [49], the fluorescence intensity decreases when the delocalization of the negative charge of the fluorescein is reduced. Therefore, an exaltation of the fluorescence has to accompany these ions exchanges and the anions of the test mixture appear as positive peaks.

To limit this lack of reproducibility between two analyses, we considered the effect of the coating time on the stability of the TTAB hemimicelles adsorbed on the capillary walls. For coating times superior or equal to two hours, we can observe a good reproducibility during 6 or 7 analyses, as much for the migration times as for the peak heights. In such conditions, it is interesting to note that the studied anions are visualized systematically as negative peaks while the negative drift of the baseline is clearly less pronounced than previously (Fig. 1B). So in order to limit this drift, that can alter the precision of quantitative analyses, we have attempted to limit its extensiveness by optimizing successively the ionic strength and the fluorescein concentration. Nevertheless, as previously mentioned, the concentration limit of detection (LOD) depends equally on the TTAB concentration in the running electrolyte. So we began the optimization of our electrophoretic system by studying this experimental parameter.

\section{Optimization of the TTAB concentration}

Systematically, in indirect UV detection, the concentration of the electroosmotic flow modifier introduced in the buffer during the analysis is the same as that used during the coating, such an experimental approach causing no damage for the detection. On the other hand, when fluorescein is used for indirect fluorimetric detection, it appears a decrease of the signal/noise ratio due to the interaction of the fluorescein with the TTAB, as mentioned previously. Otherwise, the lack of TTAB in the running buffer induces a rapid and progressive loss of the capillary coating. This causes a poor reproducibility of the analyses but allows to estimate very low concentrations. Consequently, with this electrophoretic system, the retained TTAB concentration must inevitably correspond to a compromise. So in order to optimize this experimental parameter we have studied the evolution of the signal/noise ratio as a function of the TTAB concentration introduced into the carrier electyrolyte (Fig. 2).

It clearly appears that, in the concentration range studied, the best signal/noise ratio is reached when the TTAB concentration is about $10^{-5} \mathrm{M}$ but decreases to zero when the concentration is superior or equal to $10^{-4} \mathrm{M}$. Consequently, it seemed judicious to introduce into the running buffer a TTAB concentration equal to $10^{-5} \mathrm{M}$, the latter being the optimal concentration versus the LOD. Nevertheless, in these conditions, we rapidly noticed a shift of the migration times of analyzed species, evidencing that this concentration does not totally prevent the removing phenomena. Taking into account this observation, and in order to obtain a perfect reproducibility, it is recommended to regenerate the capillary coating every 5 or 6 analyses, by flushing this last during 1 minute with the coating electrolyte.

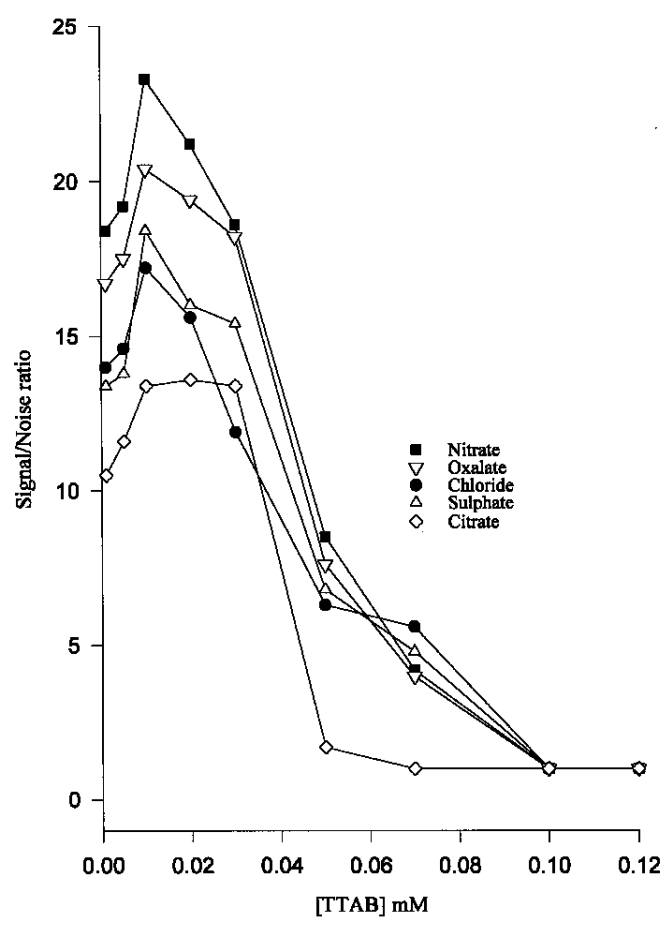

Fig. 2. Evolution of the signal/noise ratio as a function of the TTAB concentration. Operating conditions: Fused silica capillary (50 $\mu \mathrm{m}$ i.d. $\times 57 \mathrm{~cm}$ length) coated by means of TTAB; temperature $25{ }^{\circ} \mathrm{C}$; applied voltage $20 \mathrm{kV}$; running electrolyte: $\mathrm{H}_{3} \mathrm{BO}_{3}$ $10^{-1} \mathrm{M} / \mathrm{Na}_{2} \mathrm{~B}_{4} \mathrm{O}_{7} 2 \times 10^{-2} \mathrm{M}(\mathrm{pH}=8.5)$, [Fluorescein] $=10^{-5} \mathrm{M}$ and variable TTAB concentrations. Hydrodynamic injection: $4 \mathrm{~s}$; Test mixture: $\left[\mathrm{Cl}^{-}\right]=1.8 \mathrm{mM},\left[\mathrm{NO}_{3}^{-}\right]=1.8 \mathrm{mM},\left[\mathrm{SO}_{4}^{2-}\right]=0.9 \mathrm{mM}$, [oxalate $]=0.9 \mathrm{mM}$ and $[$ citrate $]=0.6 \mathrm{mM}$.

\section{Optimization of the ionic strength}

In the case of a positively charged capillary, the adsorption of mono charged anions and even more polycharged anions appears to disturb the resolution of a complex mixture. Indeed, by electrostatic attraction the injected anions can undergo more or less strong interactions with the positively charged surface induced by the adsorbed TTAB. A broadening of the solute zones then appears and therefore gives a poor efficiency. Consequently, the broadening of the solute zones have to be minimized in order to improve the mixture resolution. The evolution of the magnitude of the anions adsorption as a function of ionic strength has been followed by measuring the efficiency relating to two test anions, considered as representative of the studied mixture, namely: chloride and oxalate ions.

As evidenced in figure 3, whatever be the ion, efficiency and ionic strength simultaneously decrease. As a result to optimize the electrophoretic system efficiency, it is interesting to use a high ionic strength in order to shield the positive charges of the capillary by means of anions present within the electrolyte. However, this adsorption is still important if we consider polycharged anions, i.e. in the present case: sulphate, oxalate and citrate anions. In fact, as shown in table I, if the monocharged anions, on one hand, and the polycharged anions, on the other hand, migrated as expected from their equivalent ionic mobility [52], the migration velocity of polycharged anions appeared to be deeply decreased as compared to that of monocharged 


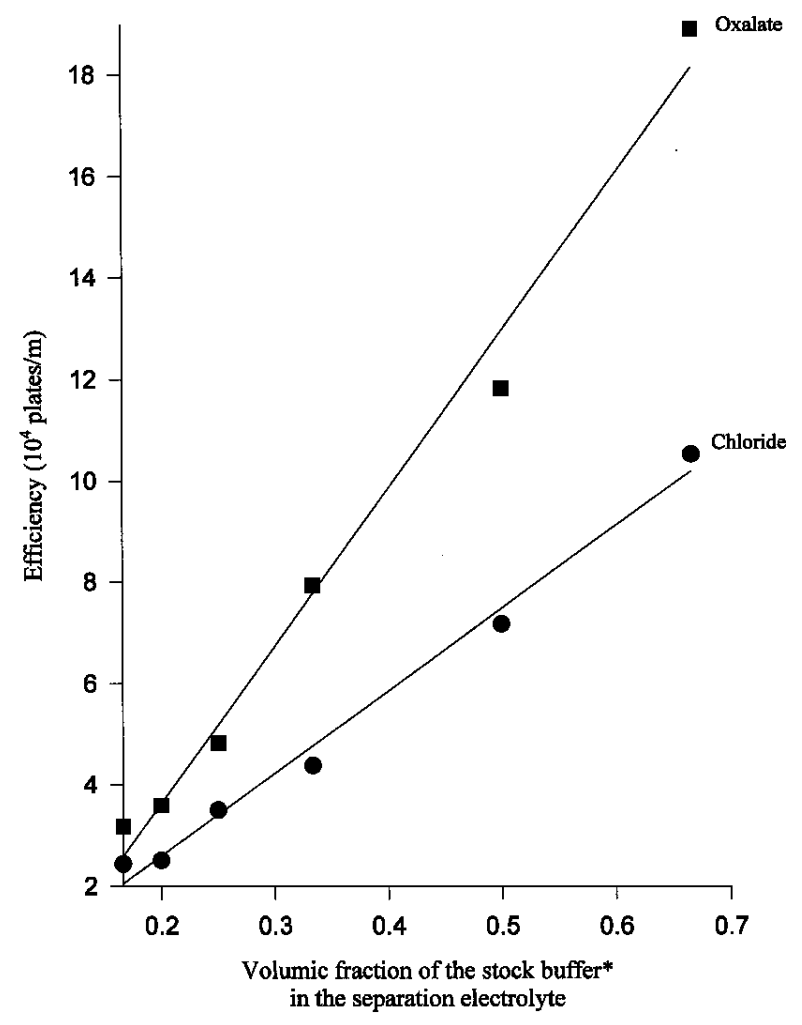

Fig. 3. Evolution of the efficiency as a function of the electrolyte ionic strength. Operating conditions: Fused silica capillary $(50 \mu \mathrm{m}$ i.d. $\times 57 \mathrm{~cm}$ ) coated by means of TTAB; temperature $25{ }^{\circ} \mathrm{C}$; applied voltage: $20 \mathrm{kV}$; electrolyte: dilution of stock buffer*, $[\mathrm{TTAB}]=10^{-5} \mathrm{M}$, [Fluorescein $]=10^{-5} \mathrm{M}$. Hydrodynamic injection: $2 \mathrm{~s}$; Test mixture: $\left[\mathrm{Cl}^{-}\right]=1.8 \mathrm{mM}$ and [oxalate] $=0.9 \mathrm{mM}$. ${ }^{*}$ Stock buffer: $\mathrm{H}_{3} \mathrm{BO}_{3} 2 \times 10^{-1} \mathrm{M} / \mathrm{Na}_{2} \mathrm{~B}_{4} \mathrm{O}_{7} 4 \times 10^{-2} \mathrm{M}(\mathrm{pH}=8.3)$.

anions. This effect is particularly important for sulphate anion.

The efficiency being strongly influenced by the electrolyte ionic strength, the resolution of the test mixture has to depend on this parameter. As a result, we have studied the evolution of the resolution as a function of the ionic strength.

Figure 4 shows that the resolution rises when the ionic strength increases, due to a greater efficiency on one hand and because of a change in selectivity on the other hand. Indeed, when the ionic strength is low, the efficiency decreases and the selectivity changes, so that the fluoride and citrate anions elution order is reversed. However the

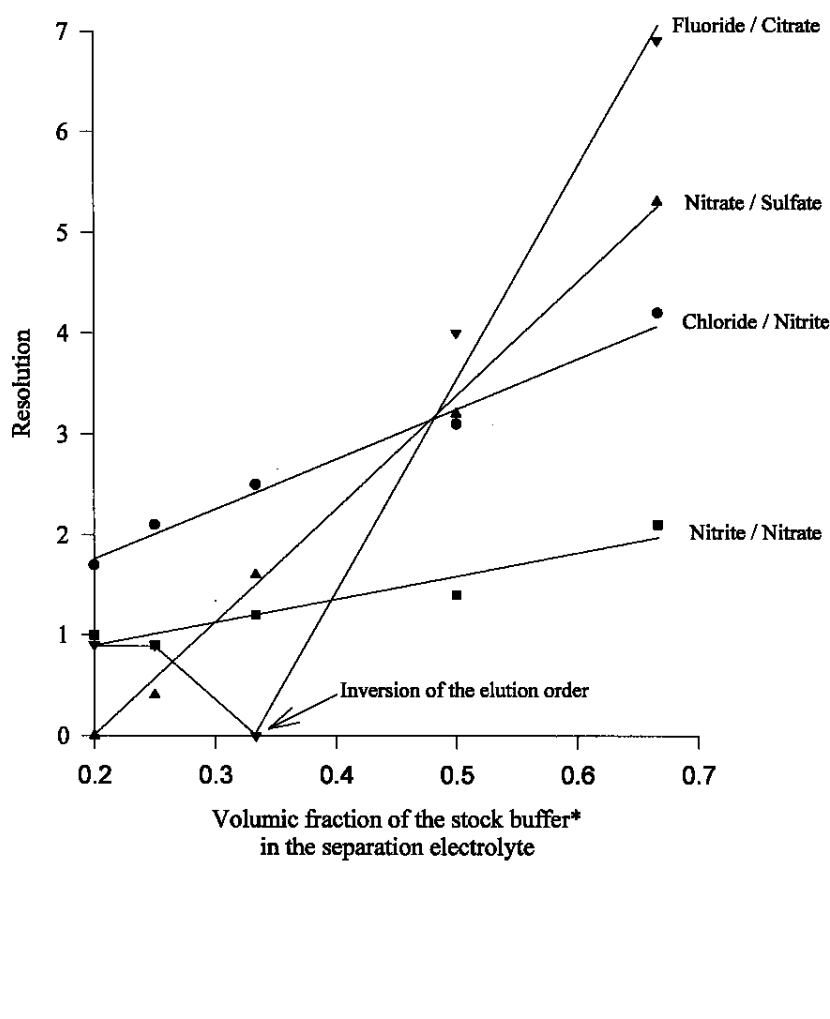

Fig. 4. Evolution of the resolution as a function of the electrolyte ionic strength. Operating conditions: as reported in figure 3, excepted the composition of the test mixture: $\left[\mathrm{Cl}^{-}\right]=1.8 \mathrm{mM},\left[\mathrm{NO}_{3}^{-}\right]=$ $1.8 \mathrm{mM},\left[\mathrm{NO}_{2}^{-}\right]=2.9 \mathrm{mM},\left[\mathrm{SO}_{4}^{2-}\right]=0.9 \mathrm{mM},\left[\mathrm{F}^{-}\right]=$ $1.2 \mathrm{mM}$ and [citrate] $=0.6 \mathrm{mM}$.

resolution becomes poor. Thus the use of a high ionic strength is required to enhance the differences of electrophoretic behaviors of the analyzed anions and to improve the system efficiency. Nevertheless this choice brings up two problems, i.e. the difficulties to dissipate the Joule heating and the decrease of the detection sensitivity.

Indeed, figure 5 evidences that for low ionic strength, the signal/noise ratio is high in spite of a poor efficiency of the electrophoretic system. The origin of such a paradoxical behavior has to be searched for in the interactions between fluorescein and ions within the electrophoretic buffer. By increasing the electrolyte concentration, interactions between fluorescein and test anions are reduced [49,50], inducing therefore an increase of the concentration limit of detection. In such conditions, a compromise between resolution and detection thresholds has to be found. In order to solve

Table I. Comparison of the elution order predicted from the equivalent ionic conductivities $(\Lambda)$ for the analyzed anions [52] with the experimental migration order obtained at high ionic strength.

\begin{tabular}{lllllll}
\hline $\begin{array}{l}\text { Elution order } \\
\text { from } \Lambda\end{array}$ & Sulphate & Chloride & Oxalate & Nitrite & Nitrate & Citrate \\
\hline $\begin{array}{l}\text { Elution order at } \\
\text { high ionic strength }{ }^{(1)}\end{array}$ & Chloride & Nitrite & Nitrate & Sulphate & Oxalate & Fluoride \\
\hline
\end{tabular}

\footnotetext{
(1) Ionic strength corresponding to the stock buffer: $\mathrm{H}_{3} \mathrm{BO}_{3} 2 \times 10^{-1} \mathrm{M} / \mathrm{Na}_{2} \mathrm{~B}_{4} \mathrm{O}_{7} 4 \times 10^{-2} \mathrm{M}(\mathrm{pH}=8.3)$.
} 


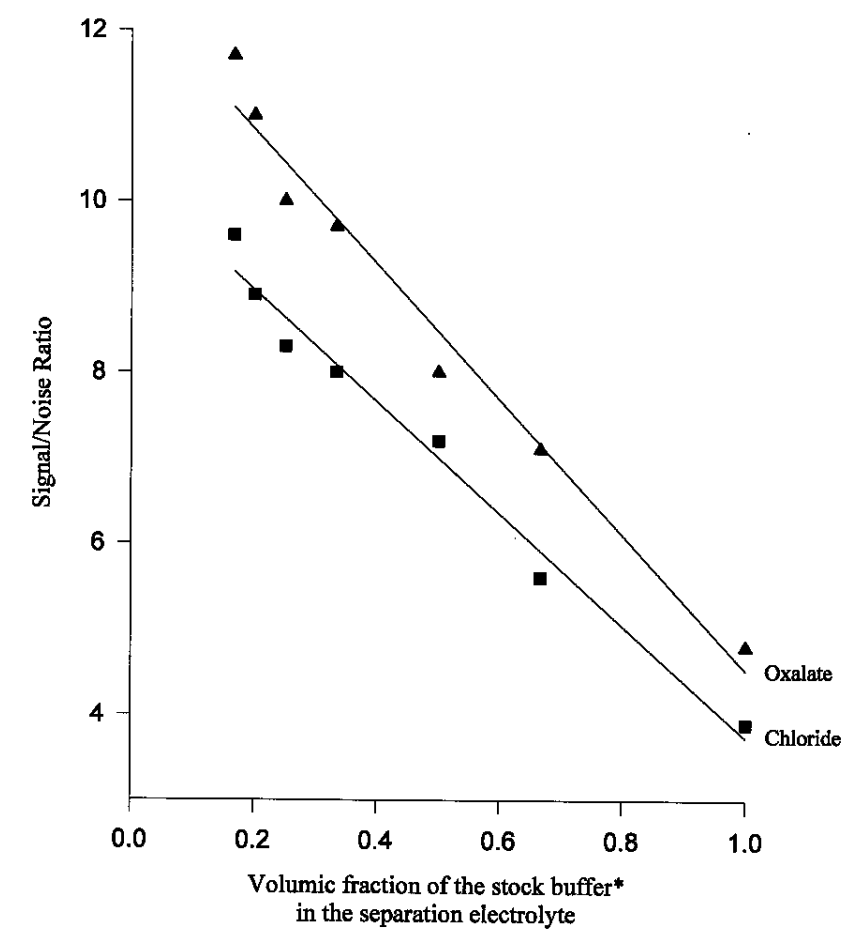

Fig. 5. Evolution of the signal/noise ratio as a function of the electrolyte ionic strength. Operating conditions: as reported in figure 3.

suitably the nitrite/nitrate pair, whose resolution is the most difficult to achieve, and to obtain furthermore a satisfactory LOD, we have retained an electrolyte based upon boric acid $0.1 \mathrm{M}$, sodium tetraborate $0.02 \mathrm{M}$, trimethyltetradecylammonium bromide $10^{-5} \mathrm{M}$ and fluorescein sodium salt $10^{-5} \mathrm{M}$. Moreover, its use led to a notable reduction of the baseline drift previously reported.

\section{Optimization of the fluorescein concentration}

To optimize the concentration limit of detection, the evolution of the signal/noise ratio has been studied as a function of the fluorescein concentration within the running buffer. This evolution is shown in figure 6 .

The reported curves show that the optimal fluorescein concentration is about of $8 \times 10^{-5} \mathrm{M}$, a concentration which is 8 times higher than that which we used in our previous works performed using bare fused silica capillaries [49,50]. This remarkable increase of the optimal fluorescein concentration probably results from the relatively strong interactions between fluorescein and the TTAB bilayer adsorbed on the capillary surface. So, owing to this fluorophore immobilization on the capillary walls, the concentration of free fluorescein is dramatically decreased as compared to that initially added within the buffer. As a result, when the concentration is inferior or equal to $8 \times 10^{-5} \mathrm{M}$, the fluorophore/solute interactions become infrequent so that a low concentration limit of detection cannot be reached. By another way, the use of buffer with a high ionic strength, in order to reduce the adsorption of analyzed anions, also contributes to such a situation. On the contrary above this optimal concentration, a saturation of the detector appears, a phenomenon that we have previously reported [49] and that equally induces an increase of LOD.

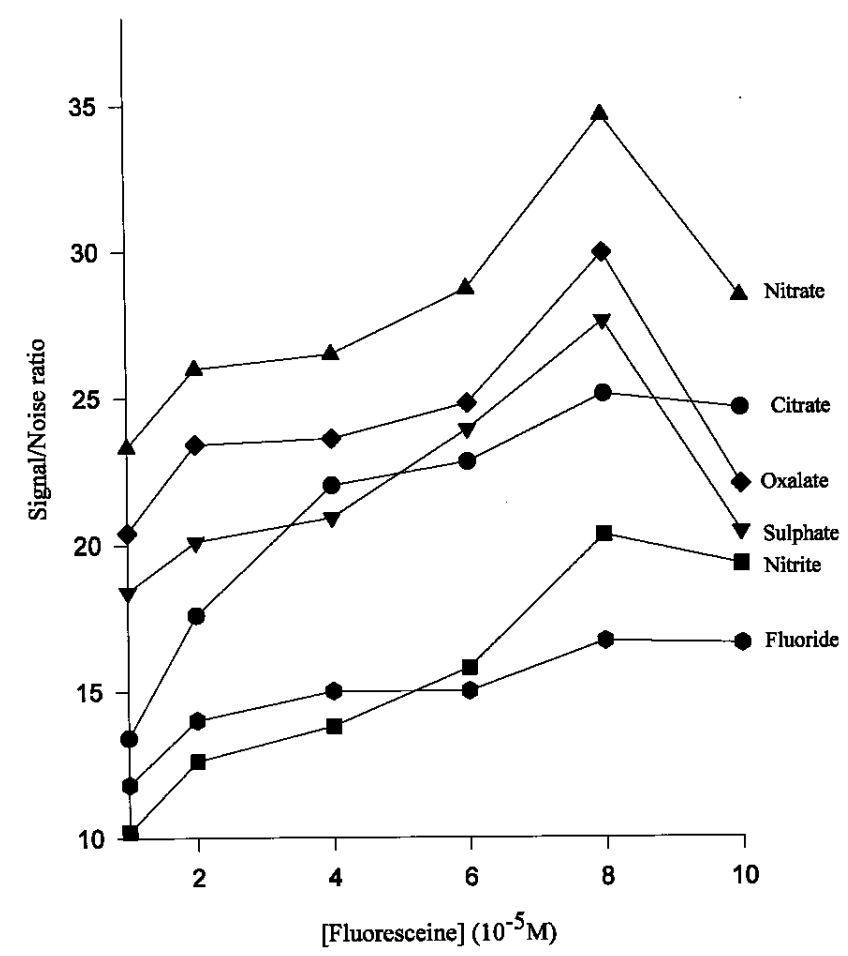

Fig. 6. Evolution of the signal/noise ratio as a function of the concentration of the fluorescein sodium salt within the electrolyte. Operating conditions: Fused silica capillary $(50 \mu \mathrm{m}$ i.d. $\times 57 \mathrm{~cm}$ length) coated by means of TTAB; temperature $25^{\circ} \mathrm{C}$; applied voltage: $20 \mathrm{kV}$; running electrolyte: $\mathrm{H}_{3} \mathrm{BO}_{3} 10^{-1} \mathrm{M} / \mathrm{Na}_{2} \mathrm{~B}_{4} \mathrm{O}_{7} 2 \times 10^{-2}$ $\mathrm{M}(\mathrm{pH}=8.5),[\mathrm{TTAB}]=10^{-5} \mathrm{M}$ and variable fluorescein concentrations. Hydrodynamic injection: $4 \mathrm{~s}$; Test mixture: $\left[\mathrm{NO}_{3}^{-}\right]=1.8$ $\mathrm{mM},\left[\mathrm{NO}_{2}^{-}\right]=2.9 \mathrm{mM},\left[\mathrm{SO}_{4}^{2-}\right]=0.9 \mathrm{mM},[$ oxalate $]=0.9 \mathrm{mM},\left[\mathrm{F}^{-}\right]$ $=1.2 \mathrm{mM}$ and [citrate $]=0.6 \mathrm{mM}$.

The electropherogram corresponding to the analysis of all the studied anions, performed in these optimized operating conditions, is shown in figure 7.

In these optimized operating conditions, we no longer observe any drift of the baseline, the progressive decrease of the background fluorescence, induced by the fluorescein/ TTAB interactions, becoming negligible in regard to the strong background signal.

The detection thresholds, obtained by performing hydrodynamic injections whose duration varies from 60 to 90 seconds, are very good: $80 \mathrm{ppb}$ for $\mathrm{Cl}^{-}, 270 \mathrm{ppb}$ for $\mathrm{NO}_{2}^{-}$, $340 \mathrm{ppb}$ for $\mathrm{NO}_{3}^{-}, 110 \mathrm{ppb}$ for $\mathrm{SO}_{4}^{2-}, 110 \mathrm{ppb}$ for $\mathrm{F}^{-}$, $140 \mathrm{ppb}$ for the oxalate ion and $280 \mathrm{ppb}$ for the citrate ion, the samples being prepared by using ultra pure water. In fact, in such conditions, a notable sample stacking can take place.

Nevertheless, the use of this new electrophoretic system is relatively difficult because of the procedure required to obtain reproducible analyses. So we intended to substitute hexadimethrine for TTAB and as a result we tested the potentialities of this polycationic surfactant. Indeed, the use of this cationic surfactant as an electroosmotic flow reverser has been previously reported in the literature [51,53,54], the magnitude of the electroosmotic flow obtained being very important. The capillary coating is performed by flushing the capillary for 20 minutes with an aqueous solution of 


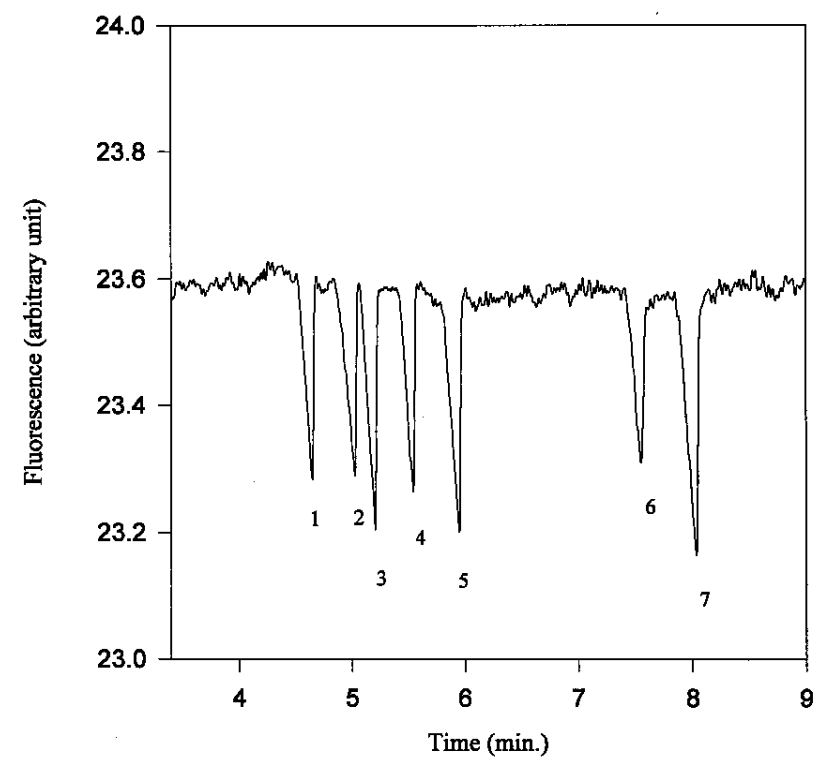

Fig. 7. Analysis of the test mixture in optimized conditions. Operating conditions: Fused silica capillary $(50 \mu \mathrm{m}$ i.d. $\times 57 \mathrm{~cm}$ length) coated by means of TTAB; temperature $25{ }^{\circ} \mathrm{C}$; applied voltage: $20 \mathrm{kV}$; running electrolyte: $\mathrm{H}_{3} \mathrm{BO}_{3} 10^{-1} \mathrm{M} / \mathrm{Na}_{2} \mathrm{~B}_{4} \mathrm{O}_{7} 2 \times 10^{-2}$ $\mathrm{M}(\mathrm{pH}=8.5),[\mathrm{TTAB}]=10^{-5} \mathrm{M},[$ Fluorescein $]=8 \times 10^{-5} \mathrm{M}$. Hydrodynamic injection: $2 \mathrm{~s}$; Test mixture: (1) $\left[\mathrm{Cl}^{-}\right]=1.8 \mathrm{mM}$, (2) $\left[\mathrm{NO}_{2}^{-}\right]=1.8 \mathrm{mM}$, (3) $\left[\mathrm{NO}_{3}^{-}\right]=2.9 \mathrm{mM}$, (4) $\left[\mathrm{SO}_{4}^{2-}\right]=0.9 \mathrm{mM}$, (5) [oxalate $]=0.9 \mathrm{mM},(6)\left[\mathrm{F}^{-}\right]=1.2 \mathrm{mM}$ and $(7)$ citrate $]=0.6 \mathrm{mM}$.

hexadimethrine $0.2 \%$. These conditions offer the advantage of insuring a sufficient stabilility to carry out several consecutive analyses without being obliged to introduce the surfactant within the buffer, namely $\mathrm{H}_{3} \mathrm{BO}_{3} 10^{-1} \mathrm{M} / \mathrm{Na}_{2} \mathrm{~B}_{4} \mathrm{O}_{7}$ $2 \times 10^{-2} \mathrm{M} \mathrm{pH}=8.5$, fluorescein $8 \times 10^{-5} \mathrm{M}$. The electropherogram obtained in these new operating conditions is shown in figure 8.

The seven previously studied anions are separated in less than 4 minutes, e.i.a time of analysis reduced by two as compared to that obtained with TTAB. Nevertheless in these new operating conditions, the resolution of the nitrite/nitrate pair is problematic and the concentration limit of detection is high. Indeed the detection thresholds of the studied anions are 3 to 5 times higher than those previously established. So the use of hexadimethrine as electroosmotic flow reverser is only interesting to reduce the analysis time and to improve the coating stability. On the contrary, its use is not suitable for traces analysis. Taking into account the detection thresholds as a criterion, we carried out the quantitative study by using TTAB as electroosmotic flow reverser.

\section{Quantitative analysis}

The reproducibility of migration times and relative migration times have been studied with sulphate ion as a reference because its migration velocity is intermediate with that of studied anions. The corresponding results reported in table II are satisfactory.

Therefore, it is possible to apply this new electrophoretic system to the quantification of $\mathrm{Cl}^{-}, \mathrm{NO}_{3}^{-}$, and $\mathrm{SO}_{4}^{2-}$ contained in various mineral and spring waters. The samples were

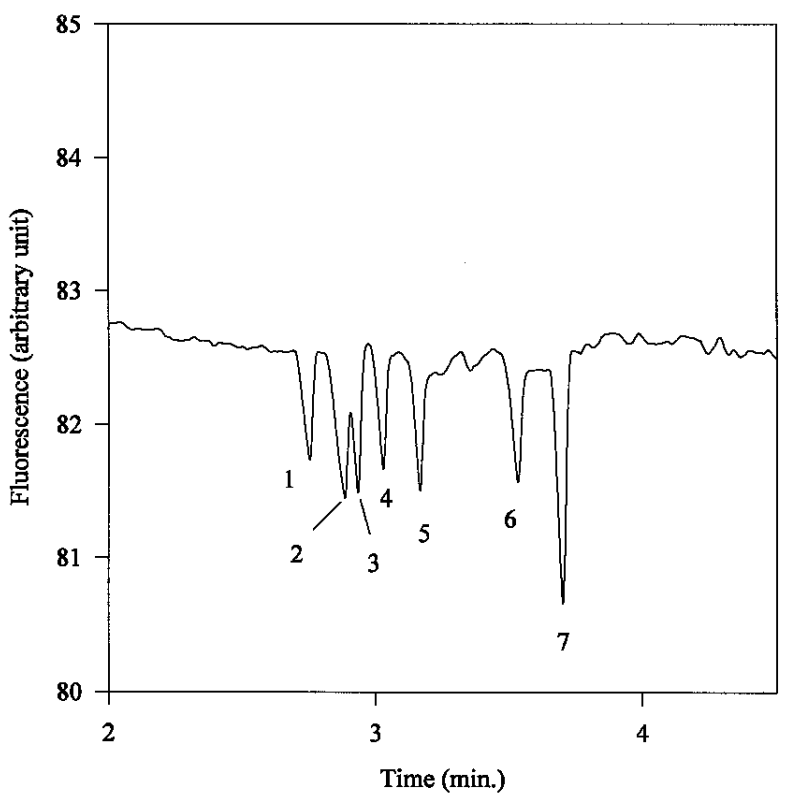

Fig. 8. Analysis of inorganic anions using hexadimethrine as electroosmotic flow reverser. Coating procedure: rinsing (20 minutes) by means of an aqueous solution of hexadimethrine $0.2 \%$ (weight percentage). Operating conditions: Fused silica capillary (50 $\mu \mathrm{m}$ i.d. $\times 57 \mathrm{~cm}$ length) coated by means of hexadimethrine; temperature $25{ }^{\circ} \mathrm{C}$; applied voltage $20 \mathrm{kV}$; running electrolyte: $\mathrm{H}_{3} \mathrm{BO}_{3} 10^{-1} \mathrm{M} / \mathrm{Na}_{2} \mathrm{~B}_{4} \mathrm{O}_{7} 2 \times 10^{-2} \mathrm{M}(\mathrm{pH}=8.5)$, [Fluorescein] = $8 \times 10^{-5} \mathrm{M}$. Before analysis: rinsing with water (1 minute), then with the running electrolyte ( 5 minutes). Hydrodynamic injection: $2 \mathrm{~s}$; Test mixture: (1) $\left[\mathrm{Cl}^{-}\right]=1.2 \mathrm{mM}$, (2) $\left[\mathrm{NO}_{2}^{-}\right]=1.9 \mathrm{mM}$, (3) $\left[\mathrm{NO}_{3}^{-}\right]=1.2 \mathrm{mM}$, (4) $\left[\mathrm{SO}_{4}^{2-}\right]=0.6 \mathrm{mM},(5)$ [oxalate $]=0.9 \mathrm{mM}$, (6) $\left[\mathrm{F}^{-}\right]=1.2 \mathrm{mM},(7)[$ citrate $]=1.2 \mathrm{mM}$.

injected by hydrodynamic mode (injection time 20 seconds), without pretreatment. Different electropherogram shapes have been obtained as shown in figure 9. It is interesting to note that the detector polarity was reversed in order to obtain positive peaks and so to realize the integration.

The quantification was performed by using an external standard, the concentration range varying from 1 to $21 \mathrm{mg}$ $\mathrm{L}^{-1}$ for $\mathrm{Cl}^{-}$, from 4 to $73 \mathrm{mg} \mathrm{L}{ }^{-1}$ for $\mathrm{NO}_{3}^{-}$and from 2 to $42 \mathrm{mg} \mathrm{L}^{-1}$ for $\mathrm{SO}_{4}^{2-}$.

Correlation coefficients were excellent for the three considered anions $\left(r=0.9992\right.$ for $\mathrm{Cl}^{-}$and $\mathrm{NO}_{3}^{-}$and $r=0.9998$ for $\left.\mathrm{SO}_{4}^{2-}\right)$. As expected, the reproducibility for corrected areas was worse for the concentrations near the detection thresholds than for the highest concentrations. Upon concentration range studied, it varied from 4 to $8 \%$ for $\mathrm{Cl}^{-}$, from 5 to $9 \%$ for $\mathrm{NO}_{3}^{-}$and from 4 to $10 \%$ for $\mathrm{SO}_{4}^{2-}$. Finally, as shown in table III, very good correlation was established between concentrations calculated by means of this new technique and those given by the commercial companies.

\section{Conclusion}

The indirect fluorimetric detection based on fluorescein sodium salt, as a visualizing agent, has been adapted for the analysis of inorganic anions and of polycharged organic anions. Such an analysis requires the use of a cationic surfactant as electroosmotic flow reverser such as, for example, 
Table II. Reproducibility of migration times $t_{\mathrm{m}}$ and of relative migration times $t_{\mathrm{rm}}{ }^{(1)}$ of the studied anions. Operating conditions: Fused silica capillary coated with TTAB $(50 \mu \mathrm{m}$ i.d. $\times 57 \mathrm{~cm}$ length) temperature $25{ }^{\circ} \mathrm{C}$; applied voltage $20 \mathrm{kV}$; electrolyte: $\mathrm{H}_{3} \mathrm{BO}_{3} 10^{-1} \mathrm{M} / \mathrm{Na}_{2} \mathrm{~B}_{4} \mathrm{O}_{7} 2 \times 10^{-2} \mathrm{M}(\mathrm{pH}=8.5),[\mathrm{TTAB}]=10^{-5} \mathrm{M}$, [Fluorescein] $=8 \times 10^{-5} \mathrm{M}$. Rinse procedure: every 4 analyses, 1 min with the following electrolyte: $\mathrm{H}_{3} \mathrm{BO}_{3} 10^{-1} \mathrm{M} / \mathrm{Na}_{2} \mathrm{~B}_{4} \mathrm{O}_{7} 2 \times$ $10^{-2} \mathrm{M}(\mathrm{pH}=8.5),\left[\right.$ TTAB] $=5 \times 10^{-4} \mathrm{M},[$ Fluorescein] $=8 \times$ $10^{-5} \mathrm{M}$. Before each analysis: $1 \mathrm{~min}$ with the running electrolyte.

\begin{tabular}{ccccc}
\hline Anions & $t_{m}$ (min.) & $\begin{array}{c}\text { R.S.D. }{ }^{(2)} \\
(\%)\end{array}$ & $t_{r m}{ }^{(1)}$ & $\begin{array}{c}\text { R.S.D. } .^{(2)} \\
(\%)\end{array}$ \\
\hline $\mathrm{Cl}^{-}$ & 4.7 & 0.4 & 0.8 & 0.2 \\
$\mathrm{NO}_{2}^{-}$ & 5.0 & 0.5 & 0.9 & 0.2 \\
$\mathrm{NO}_{3}^{-}$ & 5.2 & 0.5 & 0.9 & 0.1 \\
$\mathrm{SO}_{4}^{2-}$ & 5.5 & 0.5 & 1.0 & - \\
Oxalate & 6.0 & 0.5 & 1.1 & 0.2 \\
$\mathrm{~F}^{-}$ & 7.6 & 1.0 & 1.4 & 0.8 \\
Citrate & 8.0 & 1.5 & 1.5 & 1.4 \\
\hline
\end{tabular}

${ }^{(1)} t_{\mathrm{rm}}=t_{\mathrm{m}}$ (considered anion) $/ t_{\mathrm{m}}\left(\mathrm{SO}_{4}^{2-}\right)$.

(2) Relative standard deviation.

trimethyltetradecylammonium bromide (TTAB). TTAB/fluorescein interactions have been observed, inducing detection anomalies. To reach the maximal sensitivity, the TTAB concentration within the running electrolyte had to be reduced dramatically, in contrast to the procedures classically developed for indirect UV detection. On the other hand, the fluorescein concentration within the electrophoretic buffer had to be increased as compared to our previous works concerning the analysis of inorganic and monocharged organic anions. This change is due to fluorescein adsorption on the positively charged capillary walls. This adsorption can be reduced, although not completely suppressed, by using an electrolyte whose ionic strength has been optimized. It was demonstrated that this new electrophoretic system was very satisfactory for quantitative analysis in regard of its reproducibility, sensitivity and precision as shown by quantifying $\mathrm{Cl}^{-}, \mathrm{NO}_{3}^{-}$, and $\mathrm{SO}_{4}^{2-}$ anions in various mineral waters and spring waters.

\section{Acknowledgements}

The authors thank very sincerely Professor J.J. Aaron, Institut de Topologie et de Dynamique des Systèmes (Université D. Diderot, Paris 7), to have allowed them to use a LS-5 spectrofluorimeter (Perkin-Elmer Ltd, Beaconsfield, UK) in order to verify some of their hypotheses.

\section{References}

1. Fretz, J.; Gjerde, D.; Pohland, C. Ion Chromatography, Hüthig, New York, 1982.

2. Small, H.; Miller, T. Anal. Chem. 1982, 54, 462-469.

3. Marti, V.; Aguilar, M.; Yeung, E. J. Chromatogr. A 1995, 709, 367-374.

4. Harrold, M.; Stillian, J.; Bao, L.; Rocklin, R.; Avdalovic, N. J. Chromatogr. A 1995, 717, 371-383.

5. Kuhr, W.; Yeung, E. Anal. Chem. 1988, 60, 2642-2646.

6. Gross, L.; Yeung, E. J. Chromatogr. 1989, 480, 169-178.
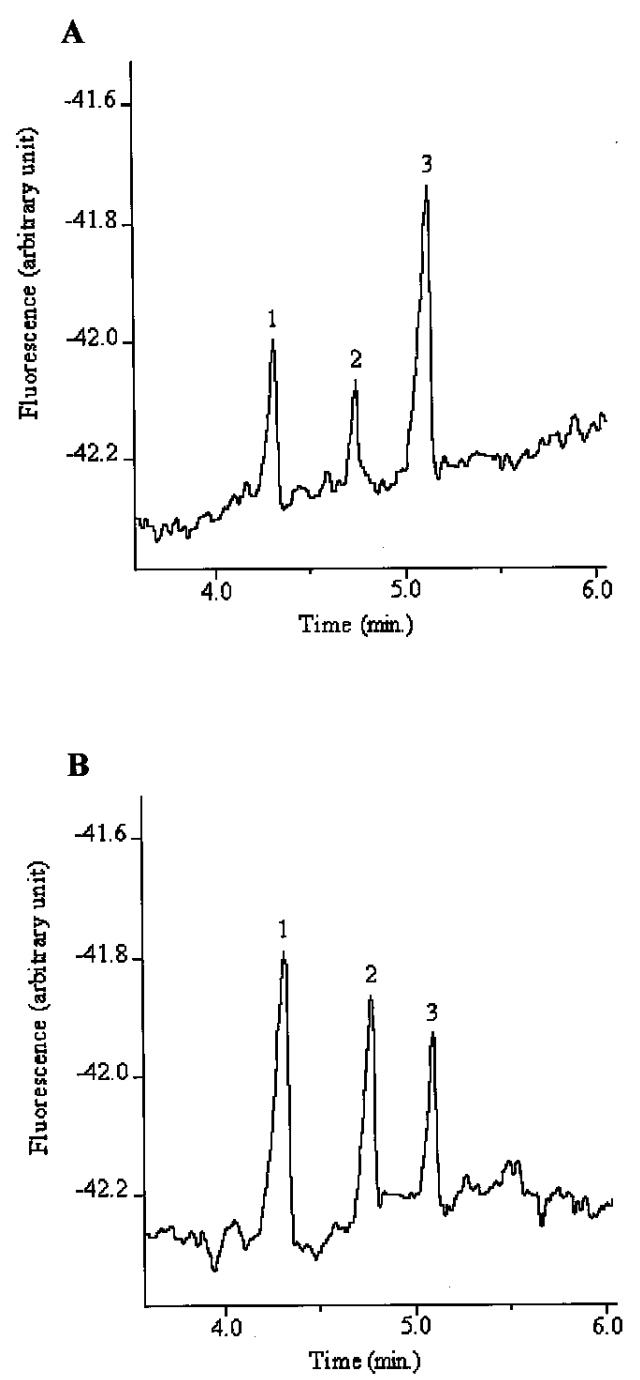

Fig. 9. Analysis of a mineral water (A) and of a spring water (B) performed in the optimal operating conditions. Operating conditions: as reported in figure 7 , excepted injection and sample. Hydrodynamic injection: 20 s. (1) $\mathrm{Cl}^{-}$; (2) $\mathrm{NO}_{4}^{2-}$; (3) $\mathrm{SO}_{4}^{2-}$.

Table III. Comparison between experimental results obtained for various mineral waters or spring waters and values given by commercial companies.

\begin{tabular}{lcccccc}
\hline & \multicolumn{2}{c}{ Chlorides } & \multicolumn{2}{c}{ Nitrates } & \multicolumn{2}{c}{ Sulphates } \\
\cline { 2 - 7 } Analyzed waters & $C_{\text {ref. }}{ }^{(1)}$ & $C_{\text {exp. }}{ }^{(2)}$ & $C_{\text {ref. }}{ }^{(1)}$ & $C_{\text {exp. }}{ }^{(2)}$ & $C_{\text {ref. }}{ }^{(1)}$ & $C_{\text {exp. }}{ }^{(2)}$ \\
\hline A (mineral water) & 4.5 & 4.5 & 3.8 & 3.7 & 10 & 12.3 \\
B (spring water) & 4 & 3.8 & 3.5 & 3.5 & 18 & 17.4 \\
C (spring water) & 13.6 & 13.3 & 12 & 12.0 & 8 & 7.5
\end{tabular}

(1) Concentrations given by the trading companies $\left(\mathrm{mg} \mathrm{L}^{-1}\right)$.

(2) Experimental concentrations $\left(\mathrm{mg} \mathrm{L}^{-1}\right)$.

7. Ma, Y.; Zhang, R. J. Chromatogr. 1992, 625, 341-348.

8. Shamsi, S.; Danielson, N. Anal. Chem. 1994, 66, 3757-3764.

9. Xue, Q.; Yeung, E. J. Chromatogr. A 1994, 661, 287-295. 
10. Dunn, C.; Hankins, M.; Ghowsi, K. Sep. Sci. Technol. 1994, 29, 2419-2433.

11. Nguyen, H.; Tamisier-Karolak, S.; Czok, M.; Laugier, R.; Cardot, P. Analusis 1995, 23, 82-87.

12. Boden, J.; Darius, M.; Bächmann, K. J. Chromatogr. A 1995, 716, 311-317.

13. Tindall, G.; Perry, R. J. Chromatogr. A 1995, 696, 349-352.

14. Salimi-Mooravi, H.; Cassidy, R. Anal. Chem. 1995, 67, 10671073.

15 Thornton, M.; Fritz, J. J. Chromatogr. A 1997, 770, 301-310.

16. Jandik, P.; Jones, W. J. Chromatogr. 1991, 546, 431-443.

17. Jones, W.; Jandik, P. J. Chromatogr. 1991, 546, 445-458.

18. Romano, J.; Jandik, P.; Jones, W.; Jackson, P. J. Chromatogr. 1991, 546, 411-421.

19. Jones, W.; Jandik, P. J. Chromatogr. 1992, 608, 385-393.

20. Cousin, S.; Haddad, P.; Buchberger, W. J. Chromatogr. A 1994, 671, 397-402.

21 Benz, N.; Fritz, J. J. Chromatogr. A 1994, 671, 437-443.

22. Li, K.; Li, S. J. Liq. Chrom. 1994, 17, 3889-3910.

23. Jimidar, M.; Hartmann, C.; Cousement, N.; Massart, D. J. Chromatogr. A 1995, 706, 479-492.

24. Song, L.; Ou, Q.; Yu, W.; Fang, L.; Sin, Y. J. Chromatogr. A 1995, 715, 376-384.

25. Guan, F.; Wu, H.; Luo, Y. J. Chromatogr. A 1996, 719, 427433.

26. Harrold, M.; Wojtusik, M.; Riviello, J.; Henson, P. J. Chromatogr. 1993, 640, 463-471.

27. Rhemrev-Boom, M. J. Chromatogr. A 1994, 680, 675-684.

28. Dabek-Zlotorzynska, E.; Dlouhy, J.; Houle, N.; Piechowski, M.; Ritchie, S. J. Chromatogr. A 1995, 706, 469-478.

29. Buchberger, W.; Haddad, P. J. Chromatogr. 1992, 608, 59-64.

30. Morin, P.; François, C.; Dreux, M. Analusis 1994, 22, 178187.

31. Stahl, R. J. Chromatogr. A 1994, 686, 143-148.

32 Devêvre, O.; Putra, D.; Botton, B.; Garbaye, J. J. Chromatogr. A 1994, 679, 349-357.

33. Song, L.; Ou, Q.; Yu, W.; Xu, G. J. Chromatogr. A 1995, 696, 307-319.

34. François, C.; Morin, P.; Dreux, M. J. High Resol. Chromatogr. 1996, 19, 5-15.
35. Willetts, M.; Clarkson, P.; Cooke, M. Chromatographia 1996, 43, 671-674.

36. Albert, M.; Debusshere, L.; Demesmay, C.; Rocca, J. L. J. Chromatogr. A 1997, 757, 291-296.

37. Nelson, B.; Uden, P.; Rockwell, G.; Gorski, K.; Aguilera, Z. J. Chromatogr. A 1997, 771, 285-299.

38. Tavares, M.; Colombara, R.; Massaro, S. J. Chromatogr. A 1997, 772, 171-178.

39. Bjergegaard, C.; Moller, P.; Sorensen, H. J. Chromatogr. A 1995, 717, 409-414.

40. Albert, M.; Demesmay, C.; Porthault, M.; Rocca, J. L. Analusis 1992, 20, 383-390.

41. Morin, P.; Amran, M.; Favier, S.; Heimburger, R.; Leroy, M. Fresenius J. Anal. Chem. 1992, 342, 357-362.

42. Amran, M.; Lakkis, M.; Lagarde, F.; Leroy, M.; LopezSanchez, S.; Rauret, G. Fresenius J. Anal. Chem. 1993, 345, 420-423.

43. Albert, M.; Demesmay, C.; Porthault, M.; Rocca, J. L. Analusis 1993, 21, 403-407.

44. Albert, M.; Debusshere, L.; Demesmay, C.; Rocca, J. L. J. Chromatogr. A 1997, 757, 281-289.

45. Chao, Y. C.; Whang, C. W. J. Chromatogr. A 1994, 663, 229237.

46. Anderson, P. E.; Pfeffer, W. D.; Blomberg, L. G. J. Chromatogr. A 1995, 699, 323-330.

47. Kennedy, S.; Caddy, B.; Douse, J. M. F. J. Chromatogr. A 1996, 726, 211-222.

48. Lee, Y. T.; Whang, C. W. J. Chromatogr. A 1996, 746, 269275

49. Desbène, P. L.; Morin, C.; Desbène-Monvernay, A.; Groult, R. J. Chromatogr. A 1995, 689, 135-148.

50. Desbène, A.; Morin, C.; Mofaddel, N.; Groult, R. J. Chromatogr. A 1995, 716, 279-290.

51. Galceran, M.; Puignou, L.; Diez, M. J. Chromatogr. A 1996, 732, 167-174.

52. Lide, D. CRC Handbook of Chemistry and Physics, CRC Press, Boca Raton, FL, 74th ed, 1993.

53. Kelly, J.; Loke, S.; Ramaley, L.; Thibault, P. J. Chromatogr. A 1996, 720, 409-427.

54. Volgger, D.; Zemann, A.; Bonn, G.; Autal, Jr. M. J. Chromatogr. A 1997, 758, 263-427. 